\title{
The Effects of Prenatal Exposure of Rabbit to Valproic Acid
}

\author{
Mohamed $\mathrm{R}^{1,2^{*}}$, Modeste $\mathrm{C}^{3}$, Beharry $\mathrm{K}^{3}$, Kheju $\mathrm{J}^{3}$, Labadie $\mathrm{D}^{3}$ and Suepaul $\mathrm{R}^{1}$ \\ ${ }^{1}$ Department of Basic Veterinary Sciences, School of Veterinary Medicine, Faculty of Medical Sciences, The University \\ of the West Indies, St. Augustine, Republic of Trinidad and Tobago; ${ }^{2}$ Department of Anatomy and Embryology, Faculty \\ of Veterinary Medicine, Beni-Suef University, Beni-Suef 62511, Egypt; ${ }^{3}$ School of Veterinary Medicine, Faculty of \\ Medical Sciences, The University of the West Indies, St. Augustine, Republic of Trinidad and Tobago
}

*Corresponding author: kkidareda@yahoo.com

Article History: 21-299 Received: 02-Apr-21 Revised: 24-May-21 Accepted: 06-Jun-21
ABSTRACT
The present study was conducted to determine the prenatal effects of sodium valproate (VPA), an antiepileptic drug,
in pregnant rabbits. Ten adult female rabbits were classified into treatment and control groups. The drug was
administrated to the treatment group as oral doses of $400 \mathrm{mg} / \mathrm{kg}$ of VPA for 15 days starting from the $6^{\text {th }}$ day after
mating until the $20^{\text {th }}$ day of pregnancy, while the control group received water at the same volume and period. The
pregnant rabbits were euthanized on the $29^{\text {th }}$ day of pregnancy. The fetuses were collected, and the crown rump length
and weight were taken. No gross or microscopic abnormalities were seen in the control group. Gross examination of
the treatment group showed reduction in size and length of the fetuses and resorption of fetuses as well as retarded
ossification, abnormal growth of the ribs and missing sternebrae. However, no abnormalities were seen
microscopically. It was found that the use of VPA during pregnancy resulted in intrauterine growth retardation
manifested by decreased fetal body weight, length, and skeletal abnormalities.

Key words: Fetus, Prenatal, Rabbit, Valproic acid.

\section{INTRODUCTION}

Valproic acid (VPA) has been widely used as an anticonvulsant drug against both generalized and partial seizures (Peterson and Naunton 2005). VPA significantly reduced body weight, crown-rump length and skull dimensions as well as axial and appendicular bones development in albino rats (Abdel Salam and Allam 2015). In humans prenatal use results in spontaneous abortions, stillbirths and spina bifida (Eadie and Vajda 2005). The risks of developing congenital malformations and neurodevelopment disorders have led to the restriction of the use of VPA for treating epilepsy or bipolar disorder in pregnant women by the European Pharmacovigilance Risk Assessment Committee (PRAC) (García-Portilla et al. 2017). A dose-effect relationship with fetal malformations and exposure to VPA was also observed in humans, where, as the dosage increased, the rate of fetal malformations also increased in the first trimester (Vajda et al. 2004). The administration of a single VPA dose $(300 \mathrm{mg} / \mathrm{kg})$ resulted in weight and length loss in rat fetuses (Baran et al. 2006), while treatment with $1200 \mathrm{mg} / \mathrm{kg}$ Valproic acid given daily resulted in a high rate $(100 \%)$ of spina bifida occulta (Ceylan et al. 2001). VPA is also neurotoxic to the Purkinje cells of the cerebellar cortex in rats (Shona et al. 2018). In rabbits, a study revealed that there was an increased incidence of fetal resorption and major malformations when given $350 \mathrm{mg} / \mathrm{kg}$ of Valproic acid on days 6-18 of gestation. In another rabbit study, Sodium valproate when used at a dose of $315 \mathrm{mg} / \mathrm{kg}$, there was an increase in renal and vertebral defects and intrauterine deaths (Whittle 1976).

Animal models are essential in preclinical antiepileptic drug research (Jagannatha 2015). The rabbit is the most sensitive and suitable laboratory animal for studying the teratogenic potential of different chemicals because developmental patterns in humans and rabbits are similar (Beaudion et al. 2003) and the rabbit's extraembryonic membranes are similar to that of humans (Foote and Carney 2002). Gross changes are easier to recognize on the rabbit fetus due to its size compared to that of rats or mice, therefore the rabbit was used as the model of choice. The aim of this study was to investigate the possible side effects in rabbits exposed to VPA $(400 \mathrm{mg} / \mathrm{kg})$ from $6^{\text {th }}$ to $20^{\text {th }}$ day of gestation.

Cite This Article as: Mohamed R, Modeste C, Beharry K, Kheju J, Labadie D and Suepaul R, 2022. The effects of prenatal exposure of rabbit to valproic acid. International Journal of Veterinary Science 11(1): 1-6. https://doi.org/10.47278/journal.ijvs/2021.070 


\section{MATERIALS AND METHODS}

\section{Animals}

This study was conducted after ethical approval (CEC 149/03/17) from the Campus Ethics Committee of the University of the West Indies, St. Augustine, Trinidad, and Tobago. Ten sexually mature, virgin, apparently healthy New Zealand and California doe rabbits were used. The rabbits aged between 5-6 months, with weights ranging between $2.8-3.4 \mathrm{~kg}$, were housed in standard cages (Fig. 1A) in a room maintained at $27^{\circ} \mathrm{C}$, with 12 -hrs light/dark cycles. They were acclimated for two weeks with access to water and a balanced commercial diet ad libitum.

\section{Experimental Protocol}

The rabbits were later placed into two groups. The treatment group contained six rabbits and the control group contained four rabbits. Does were mated with a fertile buck of the same strain. The female was housed with a male for a two-hour period in the afternoon and since ovulation occurred 10-12hrs after coital stimulation this was considered day 1 of pregnancy (Bahat et al. 2005). Sanitary conditions were maintained throughout this study; the catch pans were cleaned daily. The feed was measured daily, and the weight of rabbits was taken periodically until day 29 of gestation.

As the VPA intoxication occurred during organogenesis which was from $6^{\text {th }}$ to $18^{\text {th }}$ days of gestation (Stanley and Bower 1986; Petrere et al. 1993). Sodium valproate $\left(\right.$ Epilim $\left.^{\circledR}\right)$ syrup, $200 \mathrm{mg} / 5 \mathrm{ml}$ was orally administered once a day, from day 6 through day 20 of gestation at 12:00 hr. Enteric coated tablets (Epilim ${ }^{\circledR}$ ), $200 \mathrm{mg}$ were used for 8 weeks when there was a supply shortage of the syrup. Tablets were crushed, mixed with banana into a solution and given orally once a day (Fig. 1B). Dose administration was calculated based on per $\mathrm{kg}$ body weight per day to mirror the human therapeutic doses range of Valproic acid $400 \mathrm{mg} / \mathrm{kg}$ per day (ReaganShaw et al. 2008) Rabbits were monitored for signs of toxicity. The control group received the same volume of distilled water orally. Manual abdominal palpation was performed on day 10 of gestation until confirmed by abdominal ultrasound (Fig. 1C) by day 14 of pregnancy for all does.

\section{Sample Collection and Fetal Measurements}

All pregnant rabbits were euthanized on day 29 of pregnancy to maintain the same age for all fetuses. The abdominal cavities of the pregnant does were incised, the uteri were exteriorized, and the fetuses were extracted from their sacs (Fig. 1D\&E). The umbilical cords were clamped and cut. A total of 53 rabbit fetuses were collected ( 39 from the treatment group and 14 from the control group). Fetuses were observed for external abnormalities such as cleft palate and facial and limb deformities (Goyal et al. 2016). Crown rump length (CRL) was measured with a measuring tape, starting from the crown of the forehead along the dorsum of the fetus to the tail base. A weighing scale was used to obtain fetal weights.

\section{Skeletal Staining Technique}

Rabbit fetuses from the control and treatment groups were sacrificed to be used for this study. They were skinned and eviscerated, placed in $95 \%$ ethanol for fixation by dehydration from 4-7 days, rinsed by distilled water, put in pure acetone for 1-3 days, put in $1 \%$ potassium hydroxide solution from 1-3 days until the skeleton became clearly visible. Then they were put in a freshly prepared $0.001 \%$ Alizarin Red S solution (Fig. 1F) for skeletal staining for 24 hours until the skeleton became red. The skeletons were cleared by putting the fetuses in a mixture of $1 \%$ Potassium hydroxide and $20 \%$ glycerol for two days. Finally, they were stored in a 1:1 mixture of 95\% ethanol and glycerol. The stained axial and appendicular skeletons were examined under a Stereomicroscope for abnormalities. The gross photos were taken for documentation using a digital camera (Sony $12 \mathrm{MP}$ ). The level of ossification of the skeletons of the rabbit fetuses was estimated according to the degree of stain coloration with Alizarin Red-S, with the more highly ossified parts had a deeper red color while the incompletely ossified parts had a less red color. No color was seen in un-ossified parts (Mohamed 2018).

\section{Histopathological Examination}

Tissue specimens which included the brain, heart, lungs, liver, kidneys, forelimbs and hindlimbs, ribs and vertebrae were immediately fixed in $10 \%$ formalin following evisceration from the fetuses. After 48 hours, the specimens were dehydrated in ascending grades of ethanol concentrations, cleared in xylene, and embedded in paraffin wax. Sections of $4-6 \mu \mathrm{m}$ thickness were then deparaffinized in xylene, hydrated in a series of descending ethanol concentrations and stained with hematoxylin and eosin stain for histological examination (Alturkistan et al. 2016). Stained sections were viewed under a light microscope (Olympus BX40 with an Olympus DP74 digital camera, Japan) at different magnifications and photomicrographs were taken.

\section{Statistical Analysis}

The obtained data (lengths and weights of each litter as well as the litter size) were expressed as Mean \pm and analyzed using the Pearson correlation, the one-way ANOVA and Bonferonni post hoc.

\section{RESULTS}

\section{Gross Findings}

The gross abnormalities detected in the treatment group were underdeveloped fetus, low birth weight and fetal death (Table 1). Four dead fetuses were found with a crown-rump length of 15 to $20 \mathrm{~mm}$ indicating that they died around the $3^{\text {rd }}$ week of gestation. (Fig. 2A\&B). The stained skeletons by Alizarin red- $\mathrm{S}$ in the treatment group showed malformed ribs ( $8^{\text {th }}$ to $13^{\text {th }}$ ribs) in four rabbit fetuses (Fig. 2C) and the fourth sternebra appeared to have not developed ossification in three rabbit fetuses.

The Pearson correlation of the weight to the length of the fetuses was not significant enough to show a relationship between the two. Therefore, it can be assumed the length of the fetuses had no influence on their weight and this correlation would not affect the analysis of the Sodium valproate on each of the individual values. It also shows, it affected the rabbits in either length or weight more than the other value. The one-way 
Int J Vet Sci, 2022, 11(1): 1-6.
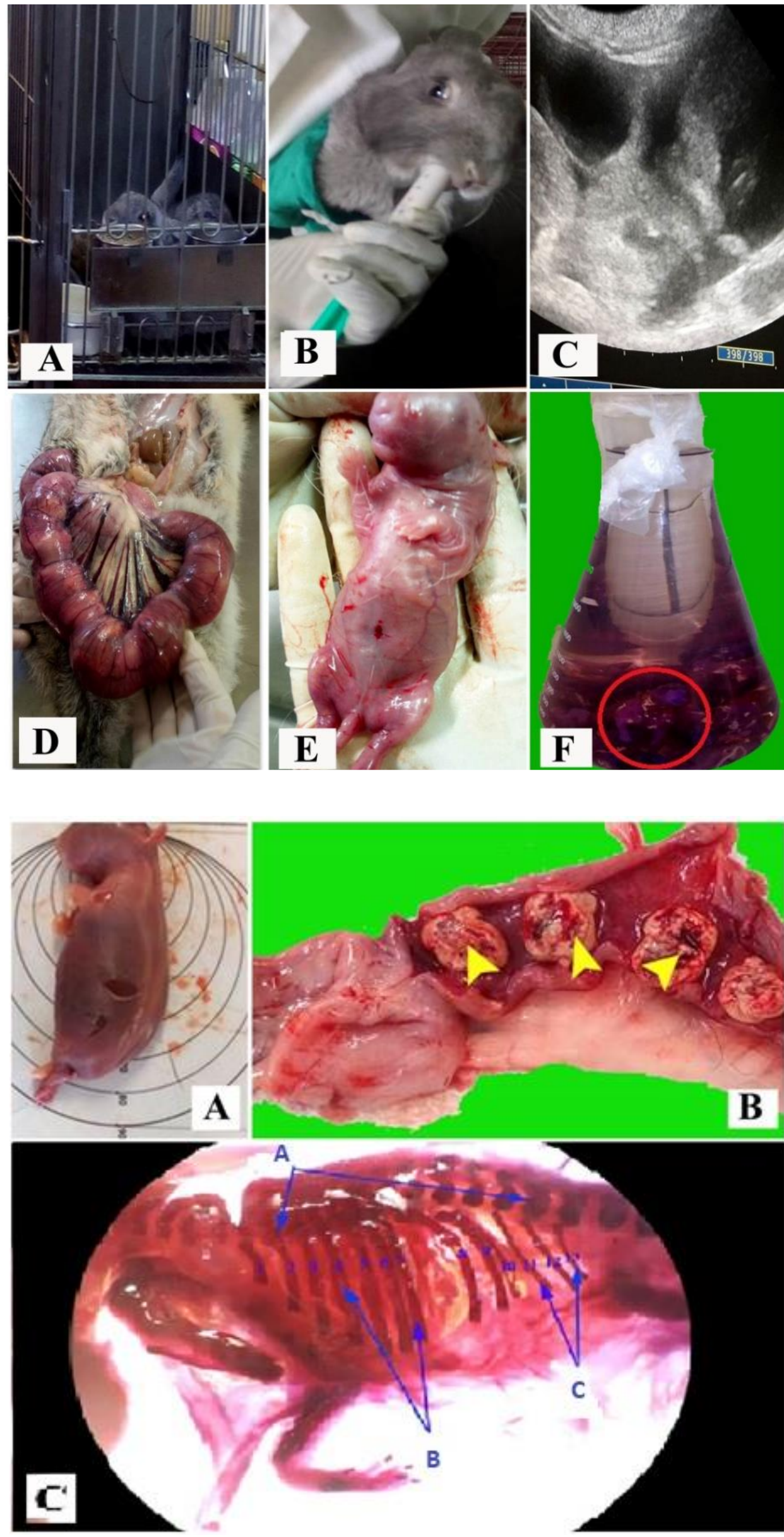
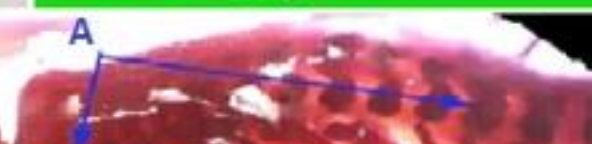

4.
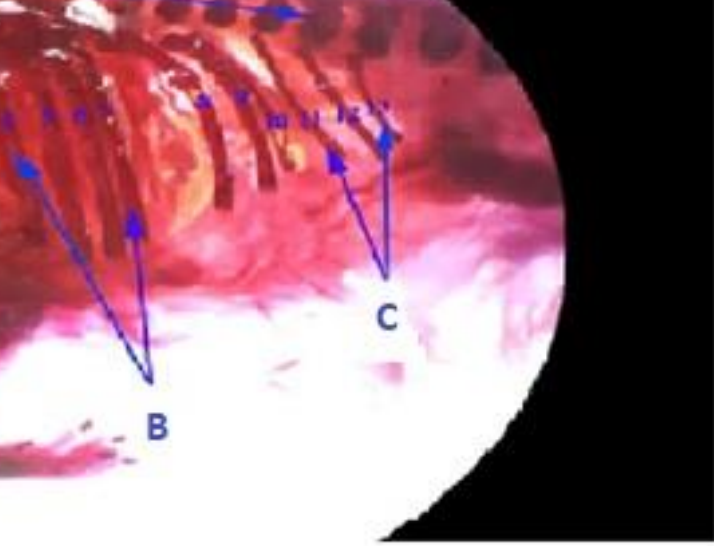

Fig. 1: A photograph showing the breeding of rabbit (A), drug administration (B), pregnancy diagnosis abdominal ultrasound (C), retrieving the fetus (D\&E) and Alizarin red S staining $(\mathrm{E})$.

Fig. 2: A photograph showing underdeveloped fetus (A), fetal resorption (B- yellow arrowheads) and rib malformations (C) Note: AThoracic vertebrae, B. Normal Ribs and C- Abnormal ribs: 1113). 
Table 1: Litter values for treatment (T) and control groups (C) indicated low birth weight and length in the treatment group

\begin{tabular}{lccc}
$\begin{array}{l}\text { Rabbit } \\
\text { Number }\end{array}$ & Litter Size & $\begin{array}{c}\text { Average Fetus } \\
\text { Length }(\mathrm{cm})\end{array}$ & $\begin{array}{c}\text { Average Fetus } \\
\text { Weight }(\mathrm{g})\end{array}$ \\
\hline T1 & 8 & 8.4 & 35.3 \\
T2 & 8 & 7.4 & 30.7 \\
T3 & 2 & 10.0 & 33.4 \\
T4 & 8 & 9.0 & 37.2 \\
T5 & 6 & 12.0 & 32.7 \\
T6 & 7 & 8.5 & 26.4 \\
C7 & 5 & 13.5 & 39.2 \\
C8 & 2 & 9.0 & 44.8 \\
C9 & 7 & 9.5 & 28.7
\end{tabular}

Table 2: Still births as well as change in the weight and length of the fetuses in the treatment group (T)

\begin{tabular}{lcc}
\hline Parameter & $\mathrm{T}$ & $\mathrm{C}$ \\
\hline Total & 39 & 14 \\
Still births & 2 & 0 \\
Mean length/cm & 9.22 & 10.68 \\
Mean weights/g & $32.6 \mathrm{~g}$ & $37.5 \mathrm{~g}$ \\
\hline
\end{tabular}

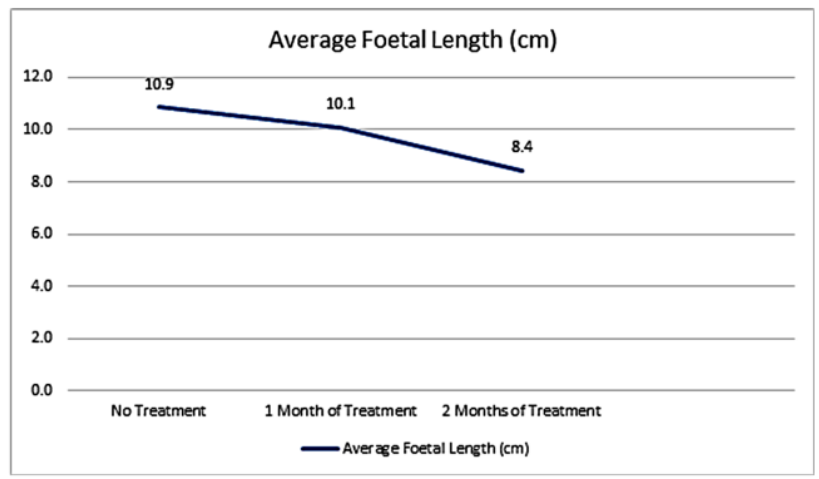

Fig. 3: The average fetal crown to rump lengths amongst treatment groups 1 month, 2 months, and no treatment.

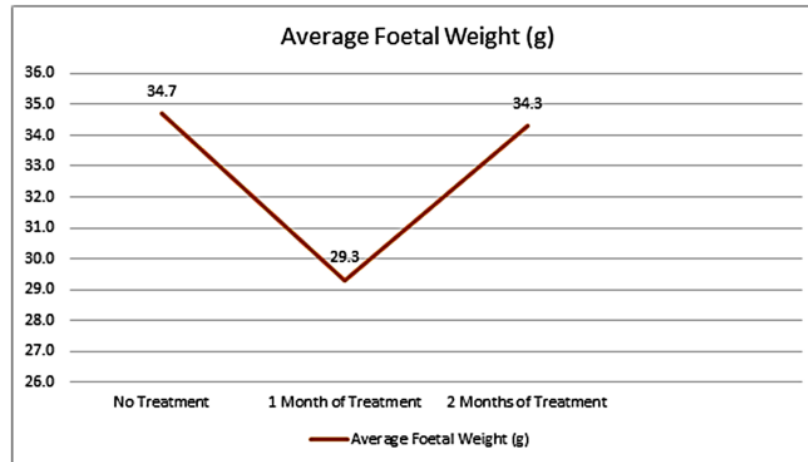

Fig. 4: The average fetal weights amongst treatment groups 1 month, 2 months and no treatment.

ANOVA showed that the Sodium valproate had an effect on the lengths of the fetus in the treatment groups for the drug $(\mathrm{F}=9.675, \mathrm{P}<0.001)$, however for the weight there was not a significant correlation $(\mathrm{F}=3.167, \mathrm{P}=0.052)$. The Bonferonni post hoc comparison was used to determine which treatment category was statistically significant from another. For mean length, it was observed that for the two treatment groups there was a significant difference between both $(\mathrm{P}=0.33)$, and no treatment for 2 months $(\mathrm{P}<0.001)$. There was no significance between treatment for 1 month and no treatment $(\mathrm{P}=0.794)$. Therefore, when the rabbits had more Sodium valproate in their system (2 months period), there was a significant change in the length of the fetus (Figs. 1-5; Table 2).

\section{Histopathological Findings}

There was no observable, histological differences between the treated and untreated fetuses. The femurs and thoracic region of the vertebral column were within normal limits (Fig. 6A and B). Hepatic architecture and renal tubular development were also within normal limits (Fig. 6C). Normal hematopoietic function of the neonatal liver was noted (Fig. 6D). The eyes were within normal limits (Fig. 6E). The left and right ventricles of the heart wer also within normal limits (Fig. 3F). The nasal septum was intact to allow the separation of the left and right nasal cavities. Lesions in the placenta indicating foetal resorption were observed (Fig. 6G). No abnormalities were detected in the brains when compare the treated to the non-treated groups (Fig. 6H).

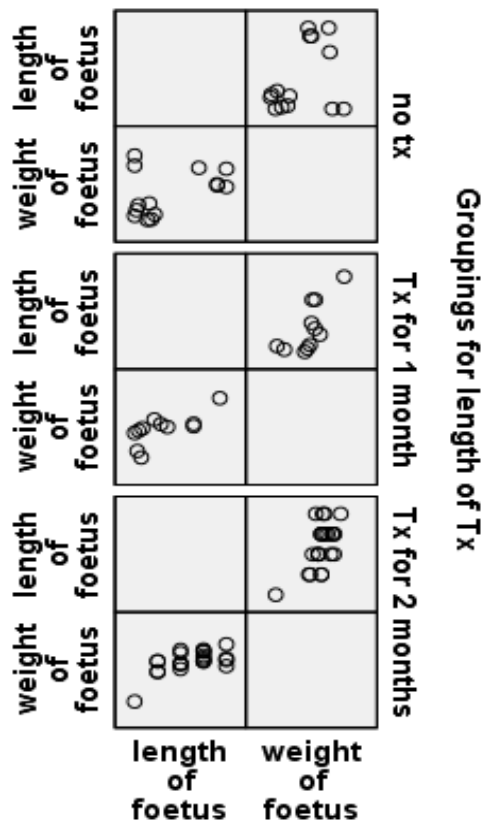

Fig. 5: A comparison of the weight and length of the fetuses amongst treatment groups month, 2 months, and no treatment.

\section{DISCUSSION}

The first scientific preference to determine the potential teratogenic effects of VPA on human health is through animal experiment. The current results showed the effects of using VPA during the pregnancy of rabbits manifested as a significant reduction $(\mathrm{P}<0.05)$ in crown rump length. There was not a significant reduction in weight. There was a significant difference in the mean length of the fetuses $(\mathrm{P}=0.033)$ between those that received treatment for two months when compared to those that received treatment for one month. Therefore, it can be noted that the longer the animal is exposed to the drugs during pregnancy, the greater the effect on the foetal crown rump length. This finding is similar to those, in pregnant albino rats, where exposure to VPA significantly $(\mathrm{P}<0.05)$ reduced all body measurements including crown-rump length, skull dimensions and body weight (Ingram et al. 2000). 

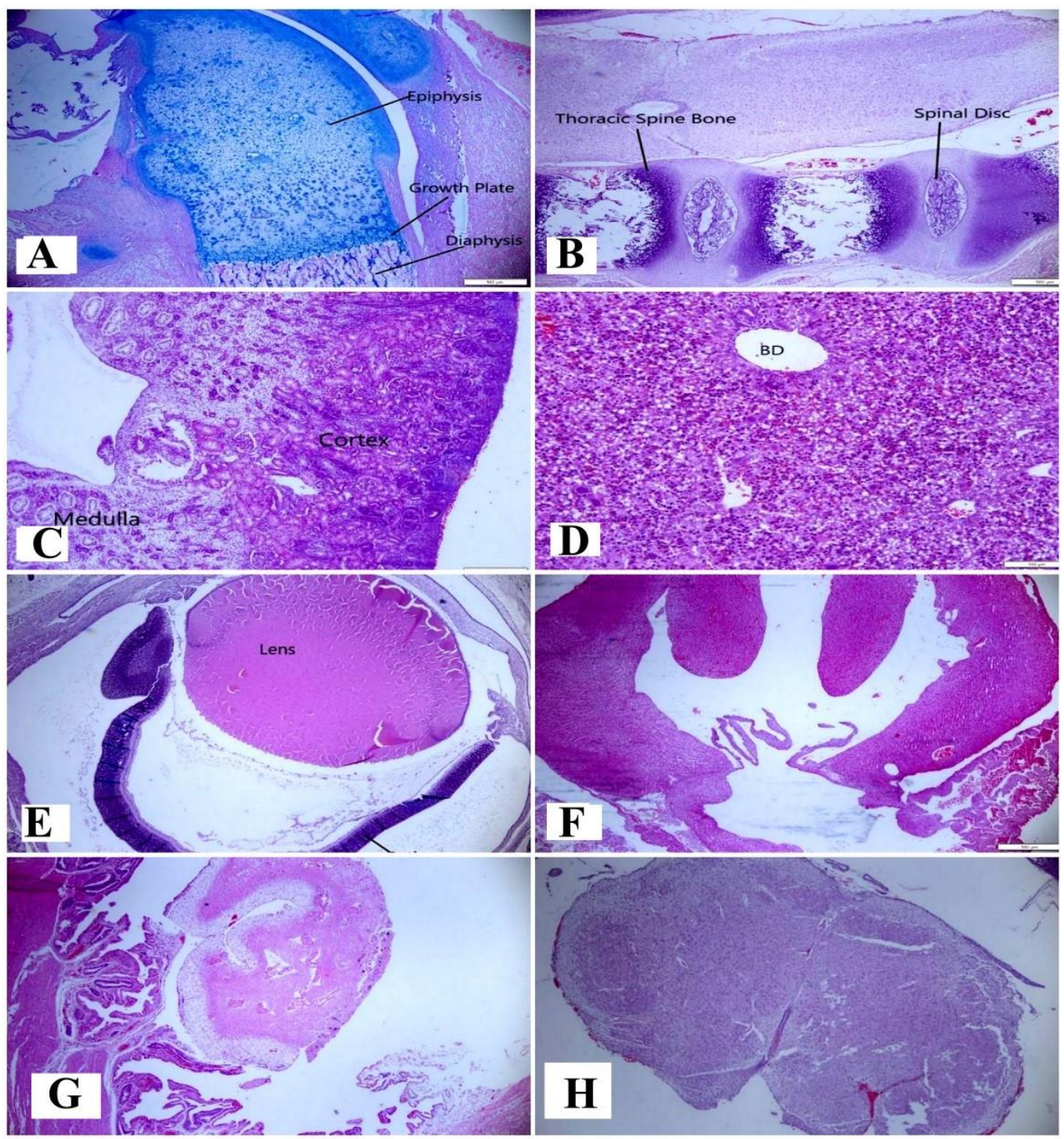

Fig. 6: A photomicrograph from the fetuses of the treatment group showing the head of the femur (A), thoracic region of the spine (B), kidney (C), liver (D), eye $€$, heart (F), placenta (G) and forebrain (H). A: Alcian Blue. B to H: H\&E. All at X40.

Sodium valproate in this study caused a decreased crown-rump length, rib malformations, fetal resorption, underdeveloped fetuses, missing sternebrae and stillbirths. These findings were similar to calcium valproate effects such as malformed ribs and post implantation loss at $350 \mathrm{mg} / \mathrm{kg}$ in rabbits (Petrere et al. 1986), malformations and loss of one sternebrae in rats (Menegola et al. 1998) as well as wavy ribs and abnormal position in the ribs (Erik-Aghaj et al. 2015) in rats. Other studies showed that the administration of Valproic acid on days 10 and 13 to pregnant rats resulted in a reduction in the number and size of offspring at parturition (Komariaha et al. 2017). The axial skeletons of rats and mice are very sensitive to the teratogenic effect of Sodium valproate especially at a dose of $300 \mathrm{mg} / \mathrm{kg}$ (Menegola et al. 1996).

The current results showed that the internal organs of the treated and untreated fetuses were morphologically normal; a similar result was found with Valproic acid (500$600 \mathrm{mg} / \mathrm{kg}$ ) in the mouse (Emmanouil-Nikoloussi et al. 2004). Petrere et al. (1986) stated that there were no teratogenic effects in rabbit treated with Calcium valproate at $50 \mathrm{mg} / \mathrm{kg}$, however, this is below the dose required treatment. Valproic acid also causes hepatotoxicity in developing rats (Khan et al. 2011; Shakya et al. 2012) and mice (Ibrahim 2012), cardiac abnormalities in mice (Wu et al. 2010), and open brain folds at a dose $300 \mathrm{mg} / \mathrm{kg}$ in mice (Menegola et al. 1996). It has a prominent neurotoxic effect on the cerebellar cortex of the adult male albino rats (Shalaby and Sarhan 2008), decreases hippocampus volume in rats (Anna Petrenko et al. 2014) and reduces cerebellar volume in rats (Ingram et al. 2000).

\section{Conclusion}

The long-term use of VPA as antiepileptic drugs during pregnancy resulted in decreased crown-rump length, rib malformations, fetal resorption, underdeveloped fetuses, missing sternebrae and stillbirths. Therefore, the use of VPA should be carefully decided for pregnant females and should not be used as a first line therapy in woman of childbearing unless it is an only option.

\section{Acknowledgments}

The authors are thankful to the technical staff and lab-assistants in the Veterinary Anatomy Department for their support and help. The research was funded by the school of Veterinary Medicine, The University of the West Indies, Trinidad and Tobago. 


\section{Authors' Contribution}

All authors contributed to the materials, analyzed the data and wrote the manuscript.

\section{REFERENCES}

Abdel Salam G and Allam AA, 2015. The effects of valproic acid on the skeletal development and the ameliorative effects of combined use of folic acid and vitamin $\mathrm{E}$ in pregnant albino rats. International Journal of Clinical and Developmental Anatomy 1: 70-78.

Alturkistan H, Tashkandi F and Mohammedsaleh Z, 2016. Histological Stains: A Literature Review and Case Study. Global Journal of Health Science 8: 72-79. https://doi.org/ 10.5539/gjhs.v8n3p72

Anna Petrenko A, Gulyaev M, Tischenko D, Petuchov V and Abbasova K, 2014. Effects of prenatal treatment with valproic acid (vpa) on offspring of epileptic adult rats: MRI investigation. Journal of Neuroscience and Neuroengineering 2: 1-7. https://doi.org/10.1166/insne.2013.1085

Bahat A, Eisenbach M and Tur-Kaspa I, 2005. Periovulatory increase in temperature difference within the rabbit oviduct. Human Reproduction 20: 2118-2121. https://doi.org/ 10.1093/humrep/dei006

Baran O, Nergiz Y and Tuncer MC, 2006. The effects of valproic acid, vitamin $\mathrm{E}$ and folic acid on the ribs of rat fetuses in the prenatal period. Annals of Anatomy 188: 117125. https://doi.org/10.1016/j.aanat.2005.11.010

Beaudion S, Barbet P and Bargy F, 2003. Developmental stages in the rabbit embryo: Guidelines to choose an appropriate experimental model. Fetal Diagnosis and Therapy 18: 422427. https://doi.org/10.1159/000073136

Ceylan S, Duru S and Ceylan S, 2001. Valproic acid sodiuminduced spina bifida occulta in the rat. Neurosurg Rev 24: 31-34. https://doi.org/10.1007/PL00011963

Eadie MJ and Vajda FJ, 2005. Should valproate be taken during pregnancy? Therapeutics and Clinical Risk Management 1: 21-26. https://doi.org/10.2147/tcrm.1.1.21.53605

Emmanouil-Nikoloussi EN, Foroglou NG, Kerameos-Foroglou $\mathrm{CH}$ and Thliveris JA, 2004. Effect of valproic acid on fetal and maternal organs in the mouse: a morphological study. Morphologie: Bulletin de L'association des Anatomistes 88 : 41-45. https://doi.org/10.1016/s1286-0115(04)97999-4

Erik-Aghaj H, Gilanpour H and Hejazi H, 2015. Study of teratologic occurrence in neonatal rat skeletal system under the effect of zonisamide and sodium valproate. International Journal of Biosciences 6: 349-354.

Foote RH and Carney EW, 2002. The rabbit as a model for reproductive and developmental toxicity studies. Reproductive Toxicology 14: 477-493. https://doi.org/ 10.1016/s0890-6238(00)00101-5

García-Portilla MP and Bobes J, 2017. Preventive recommendations on the use of valproic acid in pregnant or gestational women to be very present. Revista de Psiquiatría y Salud Mental 10: 129-133. https://doi.org/ 10.1016/j. rpsm.2017.06.001

Goyal M, Gupta A, Sharma M, Mathur P and Bansal N, 2016. Fetal valproate syndrome with limb defects: An Indian case report. Case Reports in Pediatrics 2016: 3495910. https://doi.org/10.1155/2016/3495910

Ibrahim MA, 2012. Evaluation of hepatotoxicity of valproic acid in albino mice, histological and histoistochemical studies Life Science Journal 9: 153: 159.

Ingram JL, Peckham SM, Tisdale B and Rodier PM, 2000. Prenatal exposure of rats to valproic acid reproduces the cerebellar anomalies associated with autism. Neurotoxicology and Teratology 22: 319-324. https://doi.org/ 10.1016/s0892-0362(99)00083-5

Jagannatha LS, 2015. Animal models for pre-clinical antiepileptic drug research. Science, Technology and Development 34: 82-85. https://doi.org/10.3923/std.2015.82.85
Khan M, Khattak ST and Elahi M, 2011. Gross hepatic changes in developing albino rats exposed to valproic acid. Journal of Ayub Medical College Abbottabad 23: 48-50.

Komariaha K, Kiranadib B, Winartoc A, Manalud W, Handharyanie E, 2017. valproic acid administration in pregnant rats affects litter size, birth weight, and postnatal growth of the offspring. 2017. International Journal of Sciences: Basic and Applied Research 33: 174-186.

Menegola E, Broccia ML, Prati M and Giavini E, 1998. Stagedependent skeletal malformations induced by valproic acid in rat. The International Journal of Developmental Biology 42: 99-102.

Menegola E, Broccia ML, Nau H, Prati M, Ricolfi R and Giavini E, 1996. Teratogenic effects of sodium valproate in mice and rats at mid gestation and at term. Teratogenesis, Carcinogenesis and Mutagenesis 16: 97-108. https://doi.org/10.1002/(SICI)1520-6866

Mohamed R, 2018. Alizarin Red-S protocol for skeletal staining during fetal period in rabbit. Academia Anatomica International 4: 41-44.

Petrere JA, Anderson JA, Sakowski R, Fitzgerald JE and de la Iglesia FA, 1986. Teratogenesis of calcium valproate in rabbits. Teratology 34: 263-269. https://doi.org/10.1002/ tera. 1420340305

Petrere JA, Rohn, WR, Grantham LE and Anderson JA, 1993. Food restriction during organogenesis in rabbits: effects on reproduction and the offspring. Fundamental and Applied Toxicology 21: 517-522. https://doi.org/10.1006/faat.1993. 1128

Peterson GM and Naunton M, 2005. Valproate: a simple chemical with so much to offer. Journal of Clinical Pharmacy and Therapeutics 30: 417-421. https://doi.org/ 10.1111/j.1365-710.2005.00671.x16164485

Reagan-Shaw S, Nihal M and Ahmad N, 2018. Dose translation from animal to human studies revisited. Federation of American Societies for Experimental Biology Journal 22 :659-661. https://doi.org/10.1096/fj.07-9574LSF

Shakya R, Hoque MK, Sapkota AS and Gupta PK, 2012. Histological Changes in Liver of Albino Rats Treated with Different Doses of Sodium Valproate. 2nd IASCBC \& 36th AAT Annual Conference Proceedings of the Anatomy Association of Thailand, December 6-8.

Shalaby NM and Naglaa IS, 2008. Light and electron microscopic study on the effect of valproic acid on cerebellar cortex of adult male albino rats and the possible protective effect of 1-carnitine. The Egyptian Journal of Histology 31: 256-265.

Shona SI, Rizk AA, El Sadik AO, Emam HY and Ali EN, 2018 Effect of valproic acid administration during pregnancy on postnatal development of cerebellar cortex and the possible protective role of folic acid. Folia Morphologia (Warsz) 77: 201-209. https://doi.org/10.5603/fm.a2017.0100

Stanley FC and Bower C, 1986. Teratogenic drugs in pregnancy. The Medical Journal of Australia 145: 596-599.

Vajda FJ, O'brien TJ, Hitchcock A, Graham J, Cook M and Lander C, 2004. Critical relationship between sodium valproate use and human teratogenicity: results of the Australian register of anti-epileptic drugs in pregnancy. Journal of Clinical Neuroscience 11: 854-85. https://doi.org/10.1016/j.jocn.2004.05.003

Whittle BA, 1976. Pre-clinical teratological studies on sodium valproate (Epilim) and other anticonvulsants. In: Legg NJ (ed) Clinical and pharmacological aspects of sodium valproate (Epilim) in the treatment of epilepsy. MCS Consultants, Tunbridge Wells, England, pp: 105-110.

Wu G, Nan C, Rollo JC, Huang X and Tian J, 2010. Sodium valproate-induced congenital cardiac abnormalities in mice are associated with the inhibition of histone deacetylase. Journal of Biomedical Science 17: 16. https://doi.org/ $\underline{\text { 10.1186/1423-0127-17-16 }}$ 